\title{
Arteritis de Takayasu de la Coronaria Izquierda. Presentación de un caso que debuta con muerte súbita.
}

\author{
Takayasu arteritis in the left coronary. Report of a case \\ presented as sudden death.
}

B. Aguilera y col.

Cuad Med Forense 2000;20:25-29

\begin{abstract}
Mujer de 24 años de edad, sin antecedentes patológicos. Mientras jugaba a las cartas sintió dolor precordial y sudoración, falleciendo minutos después del comienzo de la sintomatología. Se practicó autopsia forense completa. El corazón pesó $260 \mathrm{~g}$, con válvulas bien conformadas. Las coronarias se originaban en el sitio habitual, el ostium izquierdo a 2 mm por encima del anillo de inserción valvular. La coronaria izquierda, en su porción inicial, aparecía con su luz ocluida por un trombo. La coronaria derecha y las ramas izquierdas estaban permeables. El miocardio sin cambios macroscópicos. La íntima de la aorta proximal al ostium izquierdo era algo irregular, con la pared aórtica discretamente engrosada a este nivel. Estudio histológico: la pared de la arteria coronaria izquierda aparece desestructurada, con destrucción focal de las elásticas, extensa fibrosis que compromete a la íntima, capa muscular y adventicia, con trombo de fibrina adherido al endotelio, que reduce de forma importante la luz coronaria (Figura I). Se asocia a infiltrado de células inflamatorias, con predominio de linfocitos, células plasmáticas, histiocitos, algunos con transformación gigantocelular (Figuras 2 y 3). No se observó necrosis. En las muestras de miocardio no había signos de infarto reciente. No se encontraron signos de vasculitis en las muestras de coronaria derecha, descendente anterior y circunfleja, ni en las arterias sistémicas examinadas. En las muestras de aorta, en relación al ostium izquierdo, hay fibrosis intimal e infiltrado linfoplasmocitario focal en la capa media y adventicia. El cuadro morfológico, la edad y sexo del caso, son compatibles con el diagnóstico de arteritis de Takayasu. El análisis químico-toxicológico fue negativo.
\end{abstract}

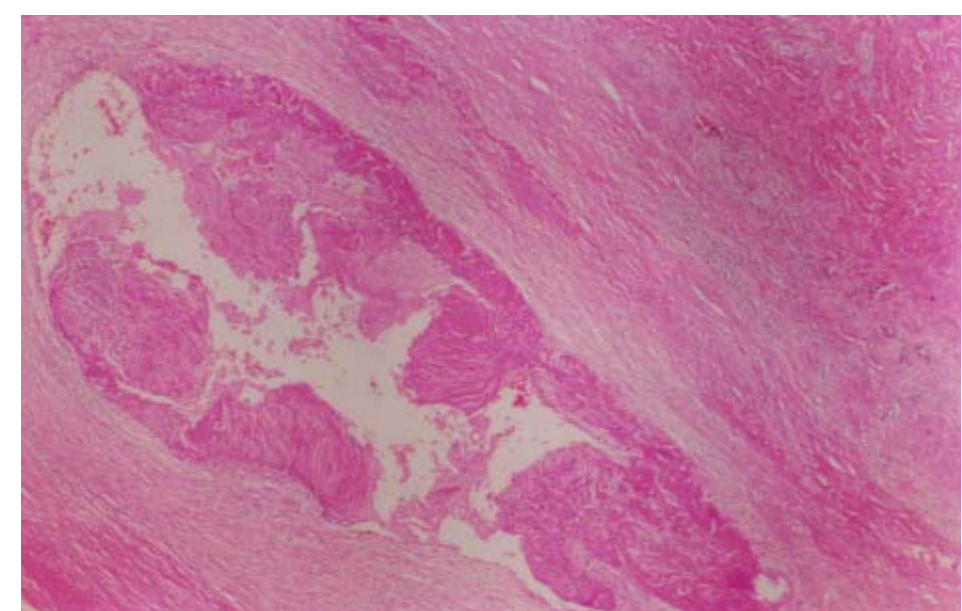

Figura 1.- Coronaria izquierda con extensa fibrosis transparietal y trombo que ocluye su luz (HE 4x). 


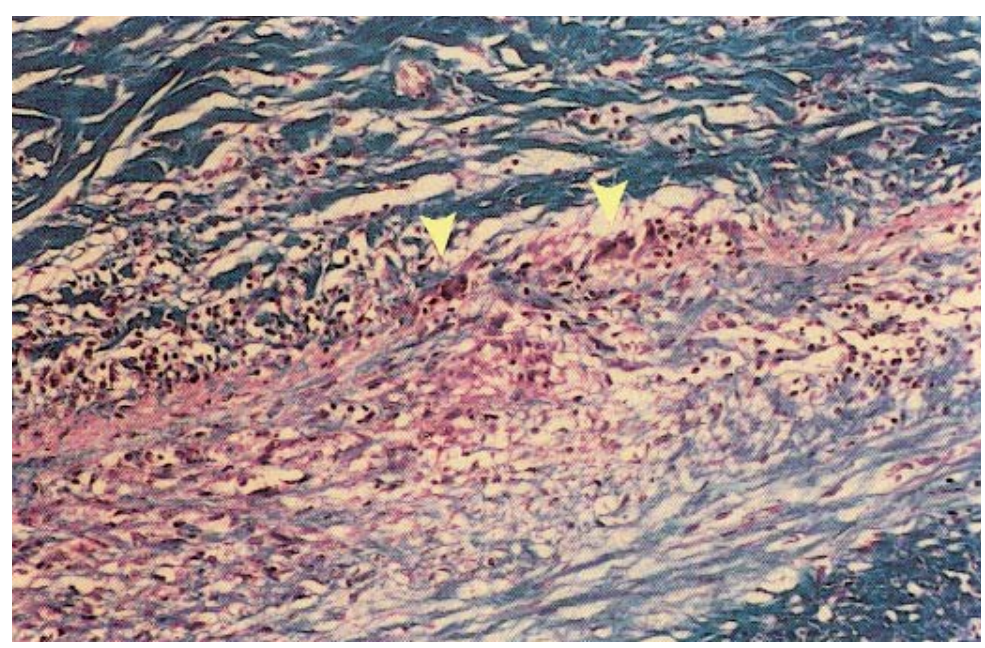

Figura 2.- Pared de la arteria coronaria izquierda muy desestructurada por fibrosis intimal y de la capa media, infiltrada por abundantes linfocitos, células plasmáticas, histiocitos y células multinucledas (puntas de flecha) (Masson 10x).

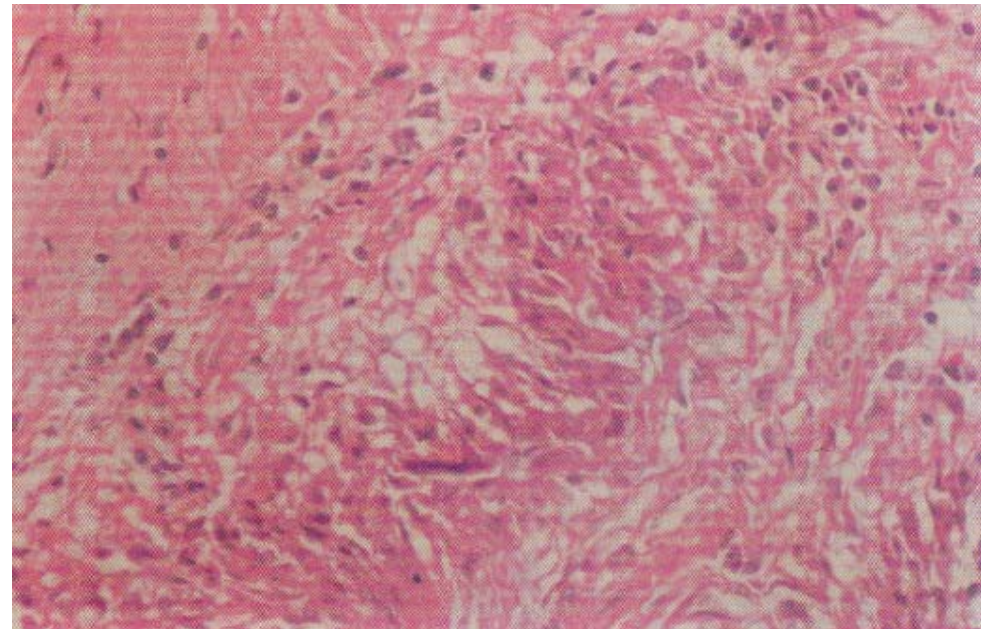

Figura 3.- Un detalle del infiltrado inflamatorio con histiocitos y células gigantes multinucleadas en la pared de la coronaria izquierda (HE 25x). 